\title{
Evaluation of lateral throat form-an in vivo study
}

\author{
Isha Rastogi \\ MDS Prosthodontics Senior Resident Mayo Institute of Medical Sciences Barabanki Up \\ E-mail: excellent123@gmail.com
}

\begin{abstract}
Introduction: Lateral throat form is an area situated at the distal end of the alveololingual sulcus. Its synonyms are distolingual vestibule and retromylohyoid fossa. The extension of denture into this area can resist horizontal forces, increase border sealing, prevent the tongue from returning to its polished surface, act as a displacing lever on the denture border and contribute to neuromuscular control.

Purpose: To evaluate the relative proportion of the lateral throat forms in 74 patients aged between 18-45 years from Lucknow(Eastern UP).A designed instrument was used to confirm LTF.

Method: LTF was intraorally evaluated by finger method and instrument.Then the mandibular impressions were made and casts obtained for measurements in this study.

Results: The data obtained was subjected to statistical analysis.It was seen that majority of the lateral throat forms among the patients were class I, followed by class II and class III were rare.Extension of denture border in the distolingual region (vertically and horizontally) was found to be more in class I lateral throat form compared to class II and least for class III.Significant differences were observed between the vertical dimension in patients' mouth to that of their diagnostic casts.Vertical and horizontal dimensions correspond to each other.The lateral throat form needs to be measured, to select proper stock tray for primary impression.The custom tray has to be adjusted and extended properly to record lateral throat form with more accuracy.

Conclusion: It is concluded that lateral throat form has to be properly recorded for mandibular denture stability and for its successful fabrication.
\end{abstract}

Keywords: Lateral Throat Form (LTF), Dentilingual Vestibule, Retromylohyoid Fossa, Alveolingual Sulcus, Lingual Border Anatomy.

\section{Introduction}

The maxillary and mandibular arches are distinct in themselves.Both have distinguished landmarks and areas. Lateral throat form (retromylohyoid fossa/LTF) is the area situated at the distal end of the alveololingual sulcus. Its synonyms are distolingual vestibule and retromylohyoid fossa. This anatomical area is probably not understood in its fullest and is frequently mismanaged during making of complete dentures.It is bounded anteriorly by the mylohyoid muscle, laterally by the pear-shaped pad, posterolaterally by the superior constrictor muscle, posteromedially by the palatoglossus muscle, and medially by the tongue(Levin B 1984).

Though the lateral throat form greatly influences the fabrication of mandibular complete dentures, yet its importance is not appreciated by most of the clinicians. The extension of the denture into this area can resist horizontal forces, increases border seal, prevents tongue from returning to denture's polished surface, act as a displacing lever on the denture border and contribute in the neuromuscular control mechanism (P S Huang et al 2007)

Neil (P S Huang 2007) divided lateral throat form into 3 classes.Tallgren(P W Smith et al 1999) classified as class I being large, class II between I and III and class III being shallow and unfavorable.Sharry (1974) wrote that the distal extension of the alveolingual area is formed by the palatoglossal arch, the superior constrictor of the pharynx, the mandibuloglossus muscle fibers, and the styloglossus muscle.W.R. Laney (1983) elaborated Neil's lateral throat form. With the index finger passively contacting the curved wall of mucosa in the retromolar fossa with the tongue at rest, the patient is instructed to protrude the tongue. If the lateral throat form changes configuration so as to place heavy pressure on the finger, it is known as Class III; if the pressure is minimal or if no pressure is exerted, the lateral throat form is Class I; any position of the tissues between these extremes is a Class II lateral throat form.Ajay Gupta (2010) wrote that alveolingual sulcus is the space between the residual ridge and the tongue and extends from lingual frenum to the retromylohyoid curtain. The retromylohyoid space is very important for denture stability and retention. Neil has classified retromylohyoid space as deep, moderate and shallow. (Fig. 1)

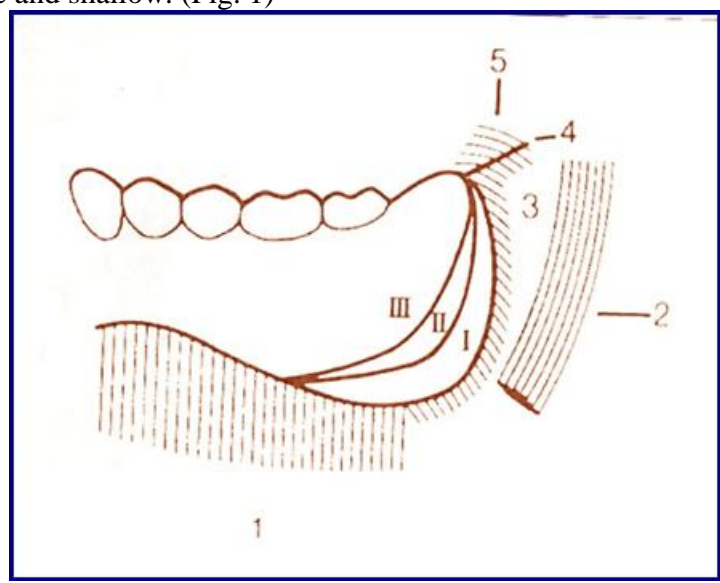

Fig. 1: Class I, II, III by Neil 
D.E. Jennings (1989) stated that retromylohyoid fossa is located below and behind the retromolar pad.Swenson(1964) wrote that distal extent of the lingual flange is partly limited by the glossopalatine arch, which is formed in part by the glossopalatine muscle and in part by the lingual extension of the superior constrictor muscle.H.A.Collett(196) wrote about referring to it as the retromylohyoid eminence because it extends beyond the distal end of the mylohyoid ridge. From an anatomic standpoint, the latter term seems to be more descriptive.Bernard D.Lynn(1964) told that lingually, the most posterior part of the alveolo-lingual sulcus is the retromylohyoid fossa.Klein E.I(1957) told that the space in which the distolingual flange rest is called the retromylohyoid space. When this sulcus does not exist in this badly resorbed mandibular edentulous mouth, the prognosis for retention is poor.W.J. Tuckfield(1950) wrote that a mechanical lock should be created in the "lateral throat form" area for the best retention of the mandibular denture.J.A. Hobkirk(1973) told that the extension of the lingual flange of the lower denture into the alveololingual sulcus can often aid stability.Galen B.Schneider(2011) wrote that the stability of the denture is supported by the primary stress-bearing areas, such as any remaining residual ridge and the buccal shelf.Engaging the retromylohyoid space also increases the lateral stability of the mandibular denture.T.E. Jacobson (1983) recommend posterior extension of the lingual flange to fill the retromylohyoid space to permit the base of the tongue to contribute to the neuromuscular control of the prosthesis. Inclination of the lingual flange must be designed to guide the tongue to rest over the flange and permit any horizontal forces generated against the denture base to be transmitted as seating forces.T.E. Jacobson (1983) stated that for retention, border molding must allow for the muscular function in the inferior portion of the retromylohyoid fossa.Arie Shifman (1984) stated that the retromylohyoid space varies greatly in shape, depth, and horizontal location.

\section{Materials and method}

This study was conducted in the department of Prosthodontics and Crown \& Bridge in Career Post Graduate Institute of Dental Sciences and Hospital, Lucknow to evaluate the relative proportion of the lateral throat forms in patients aged between 18-45 years from Lucknow(eastern UP).Instruments used were mandibular rim lock perforated dentulous trays(SSwhite instrument impression trays Germany), vibrator(Sirio Dental SNC, Model 47014, Italy)and designed instrument to verify the class of lateral throat form.

This instrument was customized.It was very simple and economical.It consisted of divider and scale.To a divider at one end, a rounded wire was adapted.In between the ends, a small scale(portion) was attached.To make it movable additionally, an opening and closing stop was attached.This instrument was used after evaluating the classification of lateral throat form intraorally and bilaterally.It served only as a verification of the classification.Its rounded end was rested on retromolar pad and slowly its stop was opened till it touched the floor of mouth.This was done for both sides and measurement was noted.The limitations were that only verification was possible, when the patient was uncooperative.(Fig.2).

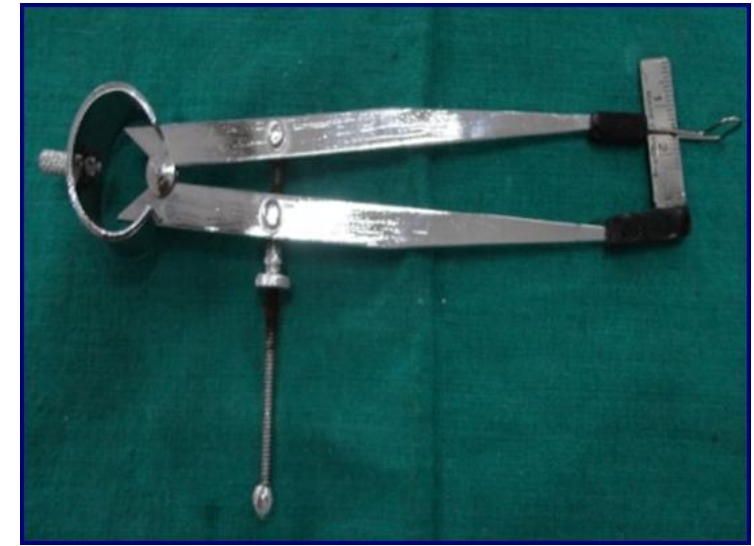

Fig. 2: Instrument and Its Parts: A-Curved Loop, B-Scale (0-30mm), CDivider, and D-Stop.

Case Selection-A total of 74 dentulous subjects were randomly selected from the local population who fell under inclusion criteria which were:

- presence of natural permanent teeth till II molar,

- age range between 18-45 years and

- Patient had adequate mouth opening.

The exclusion criteria included were that:

- there was no congenital defect in jaw,

- No abnormality in oral musculature and no distally missing teeth.

The patients were divided into four subgroups males (M) and females $(\mathrm{F})$. The males between 18 to 30 years were $\mathrm{Ma}(16)$ and those between 31-45 years were Mb (31).Similarly females who were of age between $18-45$ years were $\mathrm{Fa}(14)$ and those between 31-45 years were $\mathrm{Fb}(13)$.

\begin{tabular}{ccc}
\hline YEARS & MALES & FEMALES \\
\hline $18-30$ yrs & $16(\mathrm{Ma})$ & $14(\mathrm{Fa})$ \\
$31-45$ yrs & $31(\mathrm{Mb})$ & $13(\mathrm{Fb})$ \\
\hline
\end{tabular}

STEP 1: Determination of lateral throat form intraorally

Subject was made to sit straight in dental chair with head rested against the rest.As described by $\mathrm{Neil}^{2}$; the patient was instructed to set the tongue into a relaxed position. The examiner put his relaxed gloved index finger, lightly adapted to the patient's lingual vestibule, toward the lateral throat form. The patient was told to protrude the tongue 1/4th of an inch beyond the edge of the lower lip. If the finger felt no appreciable movement, the throat form was classified as Class I. If the finger was entirely displaced, the throat form was Class III. The throat form was Class II when the finger felt intermediate functional movement of the tissue. This classification was determined and noted for both sides ie left and right.

\section{STEP 2: Use of instrument}

After seeing which class existed intraorally, another step was verification of it.For this a customised instrument was used.The patient was asked to sit upright on dental chair with his tongue protruded one fourth of an inch beyond edge of lower lip.The instrument was placed inside the mouth.Its rounded end was rested on the retromolar pad and the other end was adjusted till it touched the floor of the mouth.The tongue was retracted with the mouth mirror and this was done on both sides. The measurements were noted so as to verify the classification with finger method(Fig $3 a, b)$. 


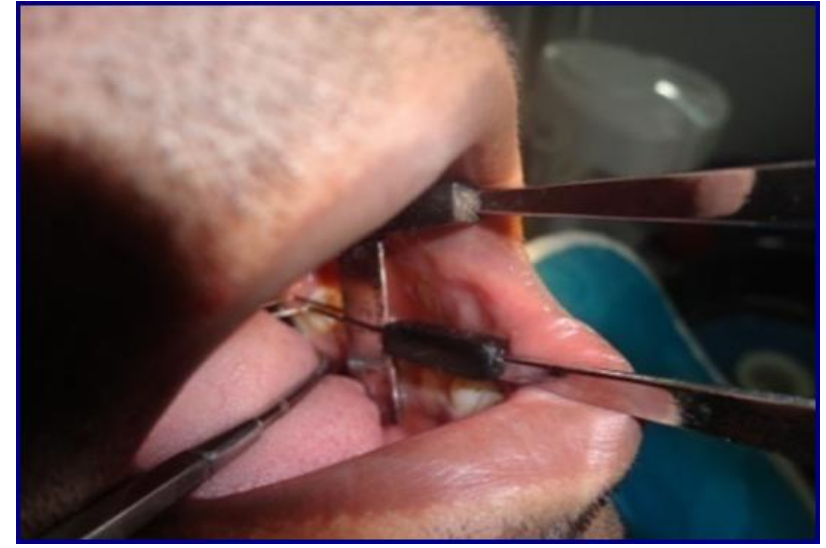

Fig. 3a: Intraoral Verification of LTF with Instrument on Patient's Left Side.

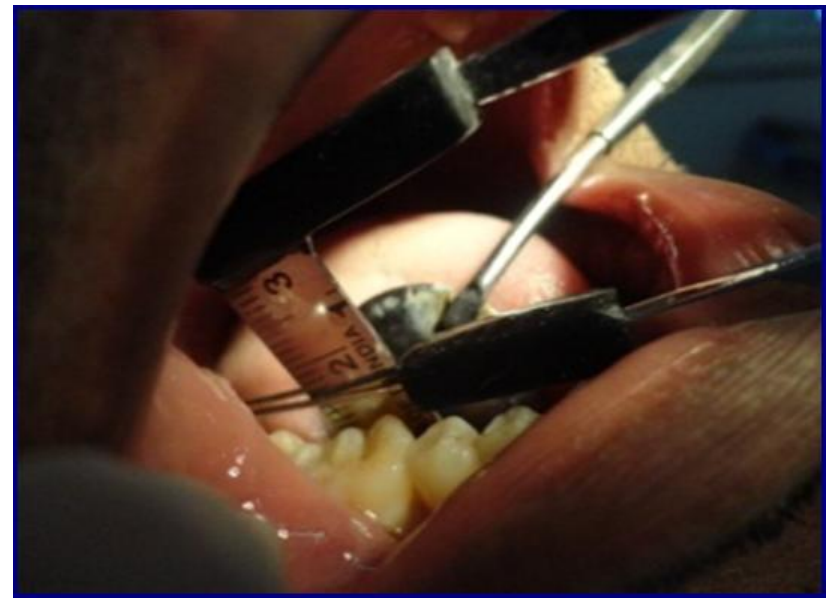

Fig. 3b: Intraoral Verification of LTF with Instrument on Patient's Righ Side.

STEP 3: an Impression making

After assessing LTF clinically by finger method and verifying it with a customized instrument, the mandibular impression of each subject was made with irreversible hydrocolloid in perforated mandibular rim lock tray.Patient was told to relax and be calm during the whole procedure.After disinfection, impressions were immediately poured with dental stone to avoid distortion and dimensional changes and cast was obtained.

STEP 3: bExtraoral measurement

After the casts had dried, using a divider and scale, the vertical and horizontal dimensions of LTF on left and right sides was determined.

1) Vertical dimension of the lateral throat form: right and left(vdr and vdl)

2) Horizontal dimension of the lateral throat form: right and left(hdr and hdl)

For the vertical dimension-from the distal end of the last permanent tooth and crest of retromolar pad till it touched the greatest depth on the distolingual vestibule.With scale and divider the dimension was noted.

For the horizontal dimension-After measuring the vertical dimension, the horizontal dimension was seen.From the vertical dimension, a horizontal extension was made at its middle most portion and extended till it reached the end of retromolar area(fold).Using scale and divider, this was noted(Fig 4a,b,c).

The values so obtained were tabulated and statistically analysed using SPSS (Statistical Package for Social Sciences) Version 15.0 statistical Analysis Software.The statistical analysis tests used were:Mean, Standard deviation, Analysis of variance, Post-hoc tests(Tukey HSD), level of significance.

\section{Results}

After statistical analysis, the results were tabulated and following inferences were drawn:

Table I demonstrated that intraorally on left side -class I had 60 , class II 10 and class III had 4 cases. The percentages were 81.1, 13.5 and $5.4 \%$ respectively for the three classes. While on the right side- class I had 63, class II 7 and class III had 4 cases. The percentage being $85.1,9.5$ and $5.4 \%$ respectively for the three classes.Totally it was seen that $83.1 \%$ people had class I, $4.7 \%$ had class II and $5.4 \%$ had class III.

Table I: .Intraoral Proportion of Lateral Throat Form

\begin{tabular}{llllllll}
\multirow{2}{*}{ S.No. } & CLASS OF LATERAL & Left & \multicolumn{3}{c}{ Right } & \multicolumn{3}{c}{ Total } \\
& THROAT FORM & No. & $\%$ & No. & $\%$ & No. & $\%$ \\
\hline 1 & I & 60 & 81.1 & 63 & 85.1 & 123 & 83.1 \\
2 & II & 10 & 13.5 & 7 & 9.5 & 17 & 4.7 \\
3 & III & 4 & 5.4 & 4 & 5.4 & 8 & 5.4 \\
\hline
\end{tabular}

Table II and III showed that class I had 60 cases, class II had 10 while class III had 4 cases. They were $81.1 \%, 13.5 \%$ and $5.4 \%$ respectively.On left side, vertical dimension's mean was 12.86 $\mathrm{mm}$ in class I, $8.45 \mathrm{~mm}$ in class II and $6.50 \mathrm{~mm}$ in class III.The standard deviation was $2.349,0.497$ and 0.577 in the three classes respectively. On left side, horizontal dimension's mean was 9.724 $\mathrm{mm}$ in class I, $7.450 \mathrm{~mm}$ in class II and $6.500 \mathrm{~mm}$ in class III.The standard deviation was 2.060 in class I, 1.606 in class II and 1.291 in class III.

Table II: Association Between Clinical Type and Vertical Dimension-on Cast (Left Side) $(\mathrm{N}=74)$.

\begin{tabular}{llllll}
\hline S.No. & Clinical Type & No. of cases & \% of total & Mean & SD \\
\hline 1. & I & 60 & 81.1 & 12.86 & 2.349 \\
2. & II & 10 & 13.5 & 8.45 & 0.497 \\
3. & III & 4 & 5.4 & 6.50 & 0.577 \\
\hline
\end{tabular}

Table III: Association Between Clinical Type and Horizontal Dimension (Left Side) $(\mathrm{N}=74)$.

\begin{tabular}{llllll}
\hline S.No. & Clinical Type & No. of cases & \% of total & Mean & SD \\
\hline 1. & I & 60 & 81.1 & 9.724 & 2.060 \\
2. & II & 10 & 13.5 & 7.450 & 1.606 \\
3. & III & 4 & 5.4 & 6.500 & 1.291 \\
\hline
\end{tabular}

Table IV and V On right side, class I had 63 cases, class II had 7 and class III had 4 cases. By percentage it was $85.1 \%$ in class I, $9.5 \%$ in class II and $5.4 \%$ in class III. On right side, vertical dimension's mean was $12.825 \mathrm{~mm}$ in class I, $8.571 \mathrm{~mm}$ in class II and $6.875 \mathrm{~mm}$ in class III. The standard deviation was 2.512 in class I, 0.535 in class II and 0.629 in class III. On right side, for horizontal dimension, percentage was $81.1 \%$ in class I, $13.5 \%$ in class II and $5.4 \%$ in class III.On right side, The mean was 10.367 $\mathrm{mm}$ in class I, $8.857 \mathrm{~mm}$ in class II and $7.125 \mathrm{~mm}$ in class III. The standard deviation was 1.750 in class I, 1.345 in class II and 1.436 in class III.

Table IV: Association Between Clinical Type and Vertical Dimension (Right Side) $(\mathrm{N}=74)$.

\begin{tabular}{llllll}
\hline S.No. & Clinical Type & No. of cases & \% of total & Mean & SD \\
\hline 1. & I & 63 & 85.1 & 12.825 & 2.512 \\
2. & II & 7 & 9.5 & 8.571 & 0.535 \\
3. & III & 4 & 5.4 & 6.875 & 0.629 \\
\hline
\end{tabular}

Table V: Association Between Clinical Type and Horizontal Dimension (Right Side) (N=74).

\begin{tabular}{llllll}
\hline S.No. & Clinical Type & No. of cases & \% of total & Mean & SD \\
\hline 1. & I & 63 & 81.1 & 10.367 & 1.750 \\
2. & II & 7 & 13.5 & 8.857 & 1.345 \\
3. & III & 4 & 5.4 & 7.125 & 1.436 \\
\hline
\end{tabular}

Table VI The discrepancy was found nonexistent in class III.It was seen that asymmetry prevailed more in class II than class I. 
Table VI: Incidence of Asymmetry (Type Discrepancy between Left and Right Sides).

\begin{tabular}{lllllll}
\hline \multirow{2}{*}{ Type Right side } & \multicolumn{3}{l}{ Type Left Side } & & & \multicolumn{2}{c}{ Type III } \\
& Type I & \multicolumn{2}{l}{ Type II } & \multicolumn{2}{c}{ No. } & $\%$ \\
\hline No. & $\%$ & No. & $\%$ & 0 & 0 \\
I & 58 & 92.1 & 5 & 6.9 & 0 & 0 \\
III & 2 & 28.6 & 5 & 71.4 & 0 & 100 \\
\hline
\end{tabular}

\section{Discussion}

The lateral throat form (Parajuli et al 2010) is a potential space located in the distolingual region of the mandibular denture bearing area. It becomes important for a Prosthodontist as it provides peripheral seal and thus retention and stability for a mandibular complete denture. Thus leading to patients' comfort and satisfaction.It is that part of the mouth in contact with the distolingual extension of the denture (Wright 1966). This area serves as the limiting factor in the downward and backward extension of lingual flange. It has profound influence on a denture success when it is meticulously utilized for retention and stability of complete dentures (Jennings 1989).

In the present study, proportion of lateral throat form was evaluated intraorally in 74 patients. Young patients were taken because the lateral throat form varies with increasing age.At older age, shallow vestibules are seen which would contradict the aim of our study that was to find randomly the proportion of lateral throat form. The dentulous group was chosen as the lingual border anatomy remains same (in both dentulous and edentulous patients).

It was seen that on left side 60 subjects $(81.1 \%)$ had class I, 10 subjects $(13.5 \%)$ had class II and 4 subjects $(5.4 \%)$ had class III. On right side 63 subjects $(85.1 \%)$ had class I, 7 subjects $(9.5 \%)$ had class II and 4 subjects (5.4\%) had class III. These results are consistent with the findings of Neil(P S Huang 2007) where proportion of class I throat form was $70 \%$, class II was $25 \%$ and proportion of class III was 5\%.These results correspond to the studies conducted by Pei-Sheng Huang (2007) and P K Parajuli(Jennings 1989).Class I is maximum depending on anatomy which is best at younger age and deteriorates as age advances. This data guides the clinician to select proper stock tray and fabricate a proper custom tray for the majority of patients.

The lateral throat form was then determined intraorally using designed instrument.It was customized to verify the lateral throat form that was noted previously with finger method.It had its drawbacks of not being used in uncooperative patients and difficulty in adjusting it.It had proved its significance by verifying the type of LTF and by recording the exact dimensions. This instrument can be used in routine practice with clinical examination to determine the LTF.

Regarding the vertical dimension of lateral throat form intraorally it was seen that on left side, in class I mean was $14.81 \mathrm{~mm}$, in class II was $9.60 \mathrm{~mm}$ and in class III was $7.50 \mathrm{~mm}$. On right side, in class I mean was $15.38 \mathrm{~mm}$, in class II was $9.57 \mathrm{~mm}$ and in class III it was $7.75 \mathrm{~mm}$.

The dentulous impressions were made with irreversible hydrocolloid as it could easily be moulded and flowed freely.Dentulous trays were used because diagnostic impressions could easily be made by them and they were comfortable both for the patient and clinician.

The vertical dimensions were then measured extraorally on cast.The vertical dimension of lateral throat form on left side extraorally on cast was determined.The mean was $12.86 \mathrm{~mm}$ in class I, $8.45 \mathrm{~mm}$ in class II and $6.50 \mathrm{~mm}$ in class III. On right side, the mean was $12.825 \mathrm{~mm}$ in class I, $8.571 \mathrm{~mm}$ in class II and $6.875 \mathrm{~mm}$ in class III. Significant differences were found between patient's mouth to that of diagnostic casts. This is in agreement with the study conducted by Pei-Sheng Huang (2007) who stated that the vertical dimension of lateral throat form in patients' oral cavities was statistically longer than in their dentures. In general most lingual flanges are too short and narrow compared to the potential vestibular space when the muscles are in normal func-
tion(Levin B 1981).This could be because in mouth the lateral throat form was recorded at its most precise extension.Also it corresponded with the study by P K Parajuli(Jennings 1989). They wrote that the border extensions of mandibular complete denture in the distolingual region, particularly in the lateral throat form were found to be significantly shorter than the available space ( $\mathrm{p}$ $0.001)$.

Extraorally on left side, leaving one case, all others in type I had vertical dimension greater than, equal to $10 \mathrm{~mm}$. Type II and type III had size less than $10 \mathrm{~mm}$. On right side, type I had vertical dimension more than, equal to $10 \mathrm{~mm}$ while in type II and III were less than $10 \mathrm{~mm}$. Vertical dimension in type I was of higher value, middle value in type II and lower value in type III. It was seen that mean vertical dimension was maximum in type I and minimum in type III. The vertical dimension in type III was of lower value while type I had a higher value. The same in type II was of middle value.

Maximum difference was observed between type I and type III and minimum between type II and type III. On both sides, the mean difference was maximum between Type I and Type III whereas the same was minimum between type II and type III. It is consistent with Levin's (1984) classification that in class I anatomical structures will accommodate a fairly long and wide flange, in class II it is about half as long and narrow as class I and about twice as long as class III and in class III it is minimum length and minimum thickness.Also this was in agreement with the description given by Sadhvi et al (2010) where the maximum value was achieved in class I, followed by class II and class III.

Extraorally the horizontal dimensions were measured.The horizontal dimension of lateral throat form on left side extraorally on cast was measured. It the mean was $9.724 \mathrm{~mm}$ in class I, 7.450 $\mathrm{mm}$ in class II and $6.500 \mathrm{~mm}$ in class III. On right side, the mean was $10.367 \mathrm{~mm}$ in class I, $8.857 \mathrm{~mm}$ in class II and $7.125 \mathrm{~mm}$ in class III. Mean horizontal dimension was maximum in Type I and minimum in Type III. Horizontal dimension in Type III was of lower value, in Type I was of higher value and of middle order in type II. Type differences were found maximum between type I and type III and minimum between type II and type III.This was because horizontal dimension is directly proportional to vertical dimension.As the vertical dimension increased, so the horizontal dimension also increased and vice versa.

It was seen that in type III, $100 \%$ symmetry ie on both sides same class was seen. While lesser symmetry ie. Different classes were observed in type I(92.1\%).However in type II maximum asymmetry ie. in most class II cases different types prevailed on both sides (71.4\%).This is justified as type III is rare and so are its discrepancies. It means type I which is the commonest presents slightly more differences on the two sides. The maximum discrepancies are seen in type II on both sides.

\section{Clinical considerations}

Even in poorest of poor conditions lateral throat form has to be recorded very critically for stability and retention of mandibular denture. The distolingual portion of the flange is influenced by the glossopalatine and superior constrictor muscles which on stretching constitute the retromyolohyoid curtain.Lateral throat form constitutes the most important bracing potential in the mandibular foundation(A Gupta 2010)

\section{Conclusion}

Within the limitations of this present study, it was observed that majority of lateral throat forms among the patients were class I, followed by class II and class III were rare.Extension of denture border in the distolingual region (vertically and horizontally) was found to be more in class I lateral throat form compared to class II and least for class III.Significant differences were revealed between vertical dimensions in patients' mouths to that of their diagnostic casts.Vertical and horizontal dimensions correspond to each 
other.The lateral throat form needs to be measured, to select proper stock tray for primary impression. The custom tray has to be adjusted and extended properly to record the lateral throat form. It is concluded that lateral throat form has to be properly recorded for mandibular denture stability and for its successful fabrication.

\section{References}

[1] Levin B. Impressions for Complete Dentures. Chicago: Quintessence, 1984:51-55

[2] Pei-Sheng Huang,Tsau-Mau Chou, Hong-Po Chang, Jen-Hao Chen, Huey-Er Lee, Hong-Sen Chen, Dorsey J. Moore. The Proportion of 3 Classes of Lateral Throat Form. International Journal of Prosthodontics 2007; 20: 640-42.

[3] P. W. Smith, R. Richmond, and J. F. McCord. The design and use of special trays in prosthodontics: guidelines to improve clinical effectiveness. British Dental Journal 1999; 187: (8), 423-426.

[4] Sharry Complete Denture, 1974; 200.Mc Graw Hill.

[5] W.R.Laney. Diagnosis and treatment in Prosthodontics, 1983: 63-64. Philadelphia, PA, Lea \& Febiger.

[6] Ajay Gupta, Himanshu. Role of Coronomaxillary Space and Lateral Throat Form in Denture Retention. BFUDJ 2010; 1: (2),25-8

[7] D.E.Jennings. Treatment of the mandibular compromised ridge: A Literature review. JPD 1989; 61:575-9.

[8] Swenson's complete dentures 5th edition, 1964,93-95 C.V.Mosby Co

[9] H.A. Collett. Complete denture impressions. JPD196;15(4), 603-614

[10]Bernard D.Lynn. The significance of anatomic landmarks in complete denture service. JPD 1964; 14 (3):456-459.

[11]Klein E.I in JPD 1957; 7:579.

[12]W.J.Tuckfield. Review of impression techniques in full denture prosthesis. Int Dent J. 1950; 1:112-130.

[13]J.A. Hobkirk. The management of gross alveolar resorption. JPD 1973; 29 (4): 397-404.

[14]Galen B.Schneider, William V. Synan. Use of a single implant to retain a mandibular complete overdenture. Special care in Dentistry, 2011; 31(4):138-143. http://dx.doi.org/10.1111/j.1754 4505.2011.00196.x.

[15]T.E. Jacobson, A. J. Krol. A contemporary review of the factors involved in complete dentures. Part II: Stability. JPD 1983; 49(1): 16572 .

[16]T.E. Jacobson, A.J. Krol. A contemporary review of the factors involved in complete dentures. Part I: Retention. JPD 1983; 49(1), 5-15.

[17]Arie Shifman. Recording the retromylohyoid space in preliminary irreversible hydrocolloid impressions. JPD 1984; 51(3), 434.

[18]Parajuli PK, Shetty TB, Shenoy VK, Rodrigues SJ. Comparative evaluation of the lateral throat form and the border extension of mandibular complete denture in the distolingual region among the south coastal Karnataka population: An in vivo study, J. Nepal Dent. Assoc. 2010; 11(2): 121-5.

[19]Corwin R.Wright. Evaluation of the factors necessary to develop stability in mandibular Dentures. JPD May-June 1966; 16(3):414-30.

[20]Levin B.Current concepts of lingual flange design.JPD 1981; 45:242252.

[21]Sadhvi K.V., Chandrasekharan Nair K., Jayakar Shetty. Research Lateral Throat Form Design of a Measuring Instrument. KDJ 2010; 33 (1), 18-19. 